\title{
THERMODYNAMICS OF FORMATION OF CHROMIUM COMPOUNDS IN WELDING AEROSOLS
}

\author{
O.G. LEVCHENKO and O.N. BEZUSHKO \\ E.O. Paton Electric Welding Institute, NASU \\ 11 Bozhenko Str., 03680, Kiev, Ukraine. E-mail: office@paton.kiev.ua
}

\begin{abstract}
Thermodynamic investigations of probability of formation of toxic chromium compounds in the composition of aerosols formed during arc welding of high-alloy steels using coated electrodes were carried out. The probability of proceeding of chemical reactions, resulting in formation of toxic chromium compounds in welding aerosols, was determined. It is shown that in the zone of welding arc in the temperature range from 1100 to $3000 \mathrm{~K}$, the formation of hexavalent chromium oxide is low probable. The calculations established that adding of titanium, silicon, manganese and aluminum into the composition of welding electrodes prevents formation of $\mathrm{CrO}_{3} .9$ Ref., 1 Table, 3 Figures.
\end{abstract}

Keywords: welding aerosols, harmful substances, thermodynamics, probability, chemical reactions, hexa valent chromium

The energy, released in the near-electrode zone of welding arc, is consumed not only for melting of materials, but also for their evaporation, resulting in formation of welding aerosol (WA) contaminating the air of working zone. Until now the processes of WA formation have been little studied because of the complex physical, chemical, physico-chemical and other processes running in the zone of welding arc. For developers of welding consumables the determination of possibility of reducing the chromium content in the composition of WA in arc welding of high-chromium-nickel steels represents a special interest.

As is known [1] in WA the chromium may be presented in trivalent state in the form of $\mathrm{Cr}_{2} \mathrm{O}_{3}$, and in hexavalent one in the form of $\mathrm{CrO}_{3}$ and also in the form of chromates and dichromates of potassium and sodium $\left(\mathrm{K}_{2} \mathrm{CrO}_{4}, \mathrm{~K}_{2} \mathrm{Cr}_{2} \mathrm{O}_{7}\right.$, $\mathrm{Na}_{2} \mathrm{CrO}_{4}, \quad \mathrm{Na}_{2} \mathrm{Cr}_{2} \mathrm{O}_{7}$ ). According to GOST 12.1.005-88 the maximum allowable concentration in the air of working zone regulated for trivalent chromium is $1 \mathrm{mg} / \mathrm{m}^{3}$, and that for hexavalent one is $0.01 \mathrm{mg} / \mathrm{m}^{3}$, i.e. hexavalent chromium may cause a harmful effect on the human body 100 times higher than trivalent chromium. Accordingly, hexavalent chromium refers to the harmful substances of the first class of hazard (extremely dangerous), and trivalent to the third class (moderately dangerous). Thus, during welding of $\mathrm{Cr}-\mathrm{Ni}$ steels the determining toxic component of WA is hexavalent chromium.

The aim of the work is the evaluation of probability and conditions of formation of chromium oxides in the composition of WA.

(C) O.G. LEVCHENKO and O.N. BEZUSHKO, 2015

To determine the probability and conditions of the reaction equilibrium the Gibbs thermodynamic function was used [2]. Changes of isobaric potential under standard conditions at a preset temperature are determined by equation (1)

$$
\Delta G_{\mathrm{t}}^{0}=\Delta H_{\mathrm{t}}^{0}-T \Delta S_{\mathrm{t}}^{0},
$$

where $\Delta H_{\mathrm{t}}^{0}, T \Delta S_{\mathrm{t}}^{0}$ are the values of enthalpy and entropy change at the temperature $T$, respectively.

The product $T \Delta S$, called a bound energy, reflects that part of the system energy, which cannot be transformed into useful work. Since the enthalpy represents a full energy reserve, the difference $\Delta H^{0}-T \Delta S^{0}$ reflects that part of energy which can be transformed into a useful work in the direction of system motion to equilibrium. Since the energy reserve is reduced here, i.e. $G_{2}<$ $<G_{1}$, then at an arbitrary running of the process $\Delta G^{0}=G_{1}-G_{2}<0$. The more $\Delta G^{0}$ decreases, the more irreversible running the process is towards the formation of reaction products.

To calculate the $\Delta G^{0}$ reactions, proceeding in welding zone at high temperatures, the approximate method [3] was used, which consists in the fact that during calculation of $\Delta G^{0}$ the enthalpy and entropy, characteristic for the reaction, are taken as being independent of temperature and those which change only as a result of their aggregate or polymorphic transformations. This is justified by the fact that the value $\Delta G^{0}$ is determined for evaluation of thermodynamic probability of reaction and degree of its moving away from equilibrium or for comparison of probability of several reactions that can occur in the same system. A small error obtained in the calculations here does not essentially affect the results of thermodynamic analysis. The calculation equations in this case are the following: 


$$
\begin{gathered}
\Delta H_{\mathrm{t}}^{0}=\Delta H_{\mathrm{t}}^{0} \pm L_{1} \pm L_{2} \pm \ldots \pm L_{n}, \\
\Delta S_{\mathrm{t}}^{0}=\Delta S_{298}^{0} \pm L_{1} / T_{1} \pm L_{2} / T_{2} \pm \ldots \pm L_{n} / T_{n},
\end{gathered}
$$

where $L_{1}, L_{2}, L_{n}$ are the corresponding values of conversion heat, $\mathrm{kJ} /$ mole; $T_{1}, T_{2}, T_{n}$ are the temperatures of phase transformations of reaction participants, K.

Due to the accepted assumption, not only the calculation of $\Delta G$ is simplified, but it is also possible to provide a simple and graphical expression of dependence $\Delta G_{t}$ on the temperature. If transformations of reaction participants are absent, the dependence is expressed in a straight line, and if present, the dependence $\Delta G_{\mathrm{t}}=f(T)$ takes the form of a broken line with bends at transformation temperatures.

The change of enthalpy in the temperature range as well as corresponding phase transformations has the following form:

$$
\begin{gathered}
\Delta H_{\mathrm{t}}^{0}=\Delta H_{\mathrm{t}}^{298}+\int_{298}^{T_{1}} \Delta C_{P 1} d T \pm L_{1}+ \\
+\int_{T_{1}}^{T_{2}} \Delta C_{P 2} d T \pm L_{2}+\ldots+\int_{T_{n}}^{T} \Delta C_{P(n+1)} d T,
\end{gathered}
$$

where $\Delta C_{P 1}, \Delta C_{P 2}, \Delta C_{P(n+1)}$ is the change of the specific heat in the course of reaction for various temperature ranges, $\mathrm{J} /(\mathrm{K} \cdot \mathrm{mole})$.

The entropy provides a key for determination of probability or improbability of thermodynamic process. The change of entropy during heating of substance from room temperature to $T$, and also at the phase and aggregate change of state of substance is the following:

$$
\begin{gathered}
\Delta S_{\mathrm{t}}^{0}=\Delta S_{298}^{0}+\int_{298}^{T_{1}} \frac{\Delta C_{P 1} d T}{T} \pm \frac{L_{1}}{T_{1}}+ \\
+\int_{T_{1}}^{T_{2}} \frac{\Delta C_{P 2} d T}{T} \pm \frac{L_{2}}{T_{2}}+\ldots+\int_{T_{n}}^{T} \frac{\Delta C_{P(n+1)} d T}{T},
\end{gathered}
$$

where $T_{1}, T_{2}, T_{n}$ is the temperature of polymorphous transformations, melting and boiling, respectively.

In case of equilibrium reaction the ratio of product of concentrations of the reaction products to product of concentrations of the starting substances is a constant value at a fixed temperature, which is called the equilibrium constant. Thus, the equilibrium constant depends only on temperature: $K=$ $=f(T)$. The equations for calculation of equilibrium constant of reaction are obtained by transformation of Van't Hoff equation [4]:

$$
\Delta G^{0}=-R T \ln K,
$$

where $R=8.314 \mathrm{~J} /($ mole $\cdot \mathrm{K})$;

$$
\ln K=-\Delta G^{0} / R T=-\left(\Delta H_{\mathrm{t}}^{0}-T \Delta S_{\mathrm{t}}^{0}\right) / R T .
$$

After replacement of the natural logarithm to the decimal one and substitution of numerical value of the gas constant $R$, we shall obtain

$$
\lg K=-\Delta H_{\mathrm{t}}^{0} / 19.1 T+\Delta S_{\mathrm{t}}^{0} / 19.1 .
$$

Having determined the change of enthalpy and entropy in the course of the reaction at a specified temperature, it is possible to calculate the equilibrium constant of the reaction.

To analyze the composition of WA, in particular, the type of chromium compounds, which may be formed in welding of alloyed $\mathrm{Cr}-\mathrm{Ni}$ steels, chemical reactions were considered, and results of thermodynamic calculations of these eight reactions are given in the Table.

In the considered cases $\Delta H_{3000}^{0}$ has a negative value, i.e. these reactions are exothermic and accompanied by heat release. Moreover, the entropy $\Delta S^{0}$ of reactions $3,4,5,7,8>0$, i.e. they proceed spontaneously, and the entropy of reactions $1,2,6<0$, which proves the impossibility of their spontaneous occurrence.

For the conditions of arc welding (at constant pressure $P=$ const) heat release (transfer) (randomly from the hot body to the cold one) is possible due to changes in enthalpy of the system $Q=\Delta H$. Moreover, it must be remembered that the enthalpy and entropy have extensive properties, i.e. they depend on the amount of substance [5].

As was noted above, to determine the probability and conditions of reaction equilibrium (in this case at $P=$ const) the Gibbs thermodynamic function $\Delta G_{\mathrm{t}}^{0}=f(T)$ was used. For reactions specified in the Table the graphic dependencies of given function were obtained (Figure 1).

In the thermodynamic system being under the constant pressure, only those processes occur randomly, which are accompanied by decrease in isobaric potential of the system, i.e. of all the possible list of chemical interactions between substances, included into the base metal and welding electrode, those reactions are possible, which would result in reduction of thermodynamic potential. Those reactions will proceed the most intensively, in which the absolute value of decrease in isobaric potential is the highest: $\left|\Delta G_{t}\right|=\max$.

Chemical affinity of substances increases their capacity to interact with formation of new substances. Obviously, that the more energy must be spent (to perform the work) to destroy the chemical bond, the higher is the value of chemical 
SCIENTIFIC AND TECHNICAL

Results of calculation of thermodynamic parameters for reactions that may proceed in the arc gap at $3000 \mathrm{~K}$

\begin{tabular}{|c|c|c|c|c|}
\hline $\begin{array}{c}\text { Number } \\
\text { of reaction }\end{array}$ & Chemical reaction & $\Delta H_{3000}^{0}, \mathrm{~kJ}$ & $\Delta S_{3000}^{0}, \mathrm{~J} / \mathrm{K}$ & $\Delta G_{3000}^{0}, \mathrm{~J}$ \\
\hline 1 & $4 \mathrm{Cr}+3 \mathrm{O}_{2}=2 \mathrm{Cr}_{2} \mathrm{O}_{3}$ & -3774.8 & -1043.62 & $-643,940$ \\
\hline 2 & $2 \mathrm{Cr}+3 \mathrm{O}_{2}=2 \mathrm{CrO}_{3}$ & -1546.486 & -920.1 & $1,213,514$ \\
\hline 3 & $4 \mathrm{CrO}_{3}=2 \mathrm{Cr}_{2} \mathrm{O}_{3}+3 \mathrm{O}_{2}$ & -594.918 & 802.6565 & $-3,002,890$ \\
\hline 4 & $2 \mathrm{CrO}_{3}+3 \mathrm{Mn}=3 \mathrm{MnO}^{2} \mathrm{Cr}_{2} \mathrm{O}_{3}$ & -1878.804 & 19.742 & $-1,938,030$ \\
\hline 5 & $4 \mathrm{CrO}_{3}+3 \mathrm{Mn}=3 \mathrm{MnO}_{2}+2 \mathrm{Cr}_{2} \mathrm{O}_{3}$ & -2820.458 & 69.84 & $-3,029,978$ \\
\hline 6 & $4 \mathrm{CrO}_{3}+3 \mathrm{Si}=3 \mathrm{SiO}_{2}+2 \mathrm{Cr}_{2} \mathrm{O}_{3}$ & -4257.198 & -57.439 & $-4,084,881$ \\
\hline 7 & $4 \mathrm{CrO}_{3}+3 \mathrm{Ti}=3 \mathrm{TiO}_{2}+2 \mathrm{Cr}_{2} \mathrm{O}_{3}$ & -2919.148 & 473 & $-4,88$ \\
\hline 8 & $2 \mathrm{CrO}_{3}+2 \mathrm{Al}=\mathrm{Al}_{2} \mathrm{O}_{3}+\mathrm{Cr}_{2} \mathrm{O}_{3}$ & -2283.639 & 1.024 & $-286,711$ \\
\hline
\end{tabular}

affinity. On the other hand, it is also clear that the more energy is released (or absorbed) during formation of chemical bond, the stronger is this bond. Consequently, the necessary condition for the process of interaction of substances is the reduction of isobaric potential of the system as a result of reaction. The absolute value of isobaric potential according to the module $\left|\Delta G_{t}\right|$ determines the value of chemical affinity, and the sign indicates the direction of chemical reaction:

$\Delta G_{\mathrm{t}}<0-$ direct reaction proceeds;

$\Delta G_{\mathrm{t}}>0$ - reverse reaction proceeds;

$\Delta G_{\mathrm{t}}=0-$ reaction is in equilibrium.

The stated regularities are true for the case when pure substances come into interaction [6].

Reaction $2 \mathrm{Cr}+3 \mathrm{O}_{2}=2 \mathrm{CrO}_{3}$ has a positive value of Gibbs energy at $3000 \mathrm{~K}$ (see Figure 1). This means that the reaction proceeds in reverse direction: $2 \mathrm{CrO}_{3}=2 \mathrm{Cr}+3 \mathrm{O}_{2}$, i.e. despite the fact that the oxidation reaction of elementary chromium must proceed according to its chemical properties, in this case in the zone of welding arc the temperature conditions are created being unfavorable for formation of hexavalent chromium.

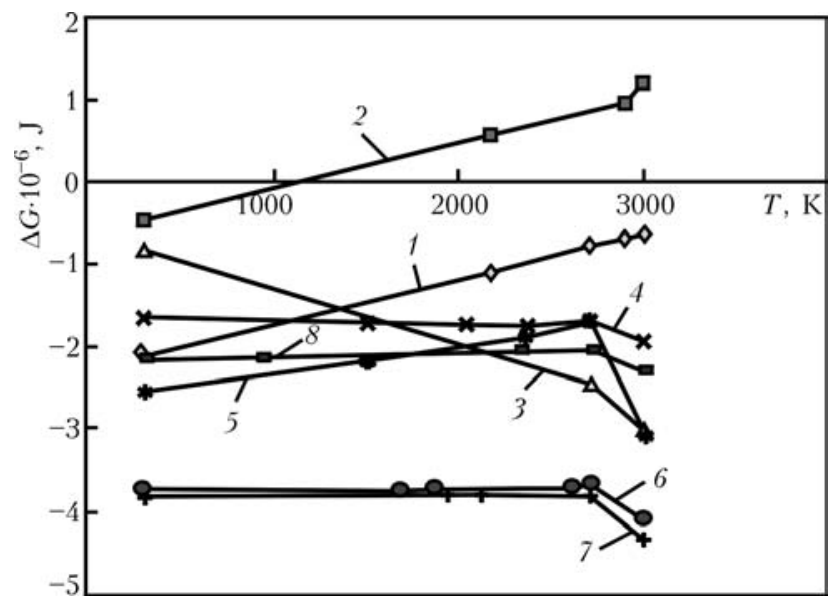

Figure 1. Graphical representation of probability of chemical reactions (numbers of curves correspond to the numbers of chemical reactions in the Table)
From the results of calculations (see Figure 1) it is seen that the most probable reactions at the change of temperature from 298 to $3000 \mathrm{~K}$ will be reactions 7 and 6 (see the Table). They evidence that the presence of such metals as titanium and silicon in the composition of welding consumables contributes to restoration of oxide of hexavalent chromium $\mathrm{CrO}_{3}$ to trivalent one $\mathrm{Cr}_{2} \mathrm{O}_{3}$. The probability of proceeding reactions 1 and 2 decreases with increase in temperature and reaching equilibrium they will proceed in the reverse direction. The curves of Gibbs energy of reactions 4 and 8 are almost parallel to each other and have a direct dependence on temperature, moreover, the probability of reaction 8 is higher than that of 4 . The latter evidences that manganese and aluminum, as well as titanium and silicon, promote restoration of hexavalent chromium oxide to trivalent oxide.

According to results of calculations it is obvious that all the considered chemical reactions (see the Table) in the range of temperatures from 298 to $3000 \mathrm{~K}$ have a high thermodynamic probability of their proceeding except of reaction 2 . At the same time if in the process of welding an elementary chromium is taken out beyond the arc gap and during decrease in temperature to $1100 \mathrm{~K}$ it is not oxidized, then at decrease of temperature lower than $1100 \mathrm{~K}$, although with low probability, the reaction of its oxidation $2 \mathrm{Cr}+3 \mathrm{O}_{2}=2 \mathrm{CrO}_{3}$ can proceed

Moreover, the results of experimental investigations [7, 8] showed that hexavalent chromium is present in the composition of WA in welding of high-alloyed steels using coated electrodes. This is explained by the fact that it is represented in WA in the form of potassium and sodium chromates $\left(\mathrm{K}_{2} \mathrm{CrO}_{4}, \mathrm{~K}_{2} \mathrm{Cr}_{2} \mathrm{O}_{7}, \mathrm{Na}_{2} \mathrm{CrO}_{4}\right.$, $\mathrm{Na}_{2} \mathrm{Cr}_{2} \mathrm{O}_{7}$ ), the formation of which is significantly affected by the content in coating of welding electrodes of alkali metal oxides $\mathrm{K}_{2} \mathrm{O}$ and $\mathrm{Na}_{2} \mathrm{O}[9]$. 


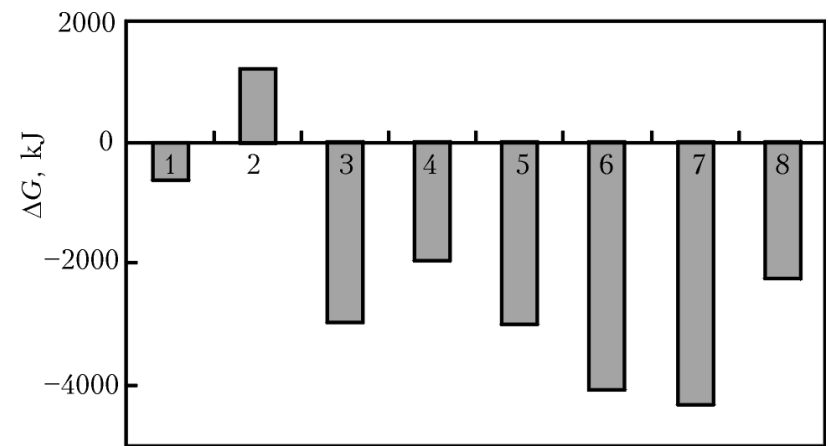

Figure 2. Change of isobaric potential of probability of chemical reactions at $3000 \mathrm{~K}$ (here and in Figure 3, digits numbers of reactions)

Analysis of thermodynamics of chemical reactions, given in the Table, allows concluding that the probability of reaction 1 of formation of chromium oxide with increase in temperature is almost reduced to zero. Reaction 2 has the lowest probability in forward direction. It is likely that at the temperature of more than $1100 \mathrm{~K}$, it will proceed in reverse direction, i.e. with decomposition of $\mathrm{CrO}_{3}$ to $\mathrm{Cr}$ and $\mathrm{O}_{2}$. Reaction 3 is likely in the given range of temperatures and has a symmetrical reflection of reaction 2 curve. This evidences that that most likely $\mathrm{CrO}_{3}$ will decay into $\mathrm{Cr}_{2} \mathrm{O}_{3}+\mathrm{O}_{2}$, but not into $\mathrm{Cr}+\mathrm{O}_{2}$. Reactions 4 and 8 have almost parallel curves, moreover, the probability of reaction 4 is a little bit higher.

Reactions 6 and 7 have the highest probability in a given range of temperatures. Reaction 5 is interesting by the fact that with increase in temperature to $2713 \mathrm{~K}$ its probability decreases, and after melting of chromium oxide $\mathrm{Cr}_{2} \mathrm{O}_{3}$ the curve has a sharp inclination in the negative direction (see Figure 1), i.e. it has a high probability at high temperatures.

We shall note that breaks in the plots of Gibbs function evidence of change in the aggregate state of final component of chemical reaction.

To compare the probability of proceeding the considered chemical reactions at the maximum temperature $(3000 \mathrm{~K})$, the histograms (Figures 2 and 3 ) are plotted. According to Figure 2 it is seen that reactions 1 and $3-8$ have a negative isobaric potential. This means that they proceed in the forward direction. At $3000 \mathrm{~K}$ reactions 7 and 6 are the most intensive. Reaction 2 does not proceed in the forward direction, it is only possible in the following form: $2 \mathrm{CrO}_{3}=2 \mathrm{Cr}+3 \mathrm{O}_{2}$. In this case, it is quite obvious that the formed elementary chromium will be oxidized in the course of reaction 1 .

From the results given in Figure 3, it is seen that at constant temperature (in this case $3000 \mathrm{~K}$ ) reactions $1-8$ will proceed, wherein reactions 7 and

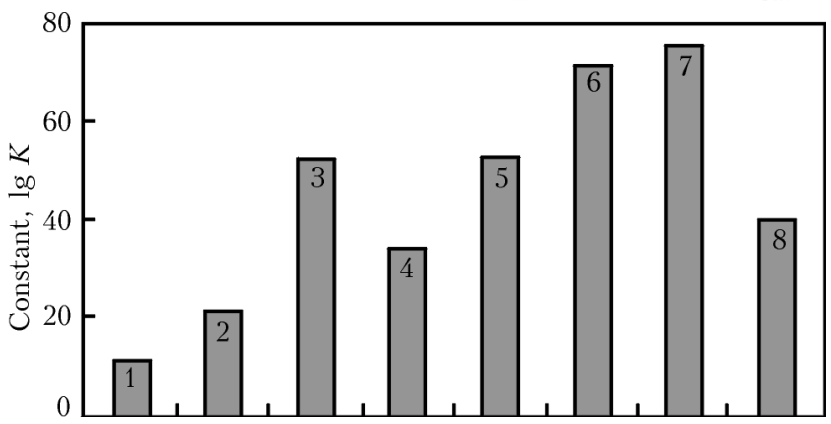

Figure 3. Equilibrium constants of chemical reactions at $3000 \mathrm{~K}$

6 will be the most intensive. The results of calculations of equilibrium constant prove that at $3000 \mathrm{~K}$ the mentioned chemical reactions can proceed almost completely. The direction of their proceeding is indicated by the sign of isobaric potential (see Figure 2).

\section{Conclusions}

1. The calculations of thermodynamic characteristics of probability of proceeding the chemical reactions of chromium oxides formation in arc welding showed that in the zone of welding arc in the temperature range from 1100 to $3000 \mathrm{~K}$ the hexavalent chromium compounds are not formed.

2 . The calculations of thermodynamic characteristics confirmed that adding of titanium, silicon, manganese and aluminum into the composition of welding electrodes can prevent the formation of hexavalent chromium oxide. At $3000 \mathrm{~K}$ the ability of these metals to prevent the formation of hexavalent chromium is increased in the following order: aluminum, manganese, silicon, titanium.

1. (1982) Researches on the origin and the characteristics of chromium in stainless steel welding fumes: IIW Doc. II-A-563-82.

2. Kokh, B.A. (1975) Principles of thermodynamics of welding thermal processes. Leningrad: Sudostroenie.

3. Rykalin, N.N. (1951) Calculations of thermal processes in welding. Moscow: Mashgiz.

4. Filippov, S.I. (1967) Theory of metallurgical processes. Moscow: Metallurgiya.

5. Devero, O.F. (1986) Problems of metallurgical thermodynamics. Moscow: Metallurgiya.

6. Bernadsky, I.I. (1978) Theory of metallurgical processes. Kiev: Vysshaya Shkola.

7. Yushchenko, K.A., Levchenko, O.G., Bulat, A.V. et al. (2007) Sanitary and hygienic characteristics of covered electrodes for welding high-alloy steels. The Paton Welding J., 12, 35-38.

8. Yushchenko, K.A., Bulat, A.V., Levchenko, O.G. et al. (2009) Effect of composition of base metal and electrode covering on hygienic properties of welding fumes. Ibid., 7, 44-48.

9. Pokhodnya, I.K., Gorpenyuk, V.N., Milichenko, S.S. et al. (1990) Metallurgy of arc welding: Processes in arc and melting of electrodes. Kiev: Naukova Dumka.

Received 18.03.2015 